\title{
DUAS TESES DE FRANZ BRENTANO SOBRE A CONSCIENCIA*
}

\author{
Denis Fisette \\ Université du Québec à Montréal
}

Wo daher das Bewußtsein [...] beginnt, beginnt das Reich der Psychologie.

F. BRENTANO

Este estudo incide sobre a teoria da consciência de Franz Brentano, na sua Psicologia de um Ponto de Vista Empírico, de 1874, e em outros escritos publicados a título póstumo. ${ }^{1}$ Proponho-me revisitar os textos de Brentano acerca da consciência à luz das interpretações divergentes de que esta teoria é objeto, tanto nos estudos brentanianos como na filosofia da mente contemporânea. Pois, se bem que a teoria da consciência de Brentano suscite atualmente bastante interesse, ela dá, igualmente, ocasião para interpretações e apreciações contraditórias acerca do sentido e do valor da sua contribuição para a filosofia da mente. Com efeito, mesmo se a interpretação dominante vai no sentido de uma aproximação da teoria de Brentano a diferentes versões das teorias de ordem superior da consciência, encontra-se também, nos estudos brentanianos, interpretações que preconizam uma aproximação de Brentano às teorias adverbiais da consciência ou ainda às teorias que se apoiam na noção

\footnotetext{
* Uma versão deste artigo foi apresentada na Universidade de Lisboa em Novembro de 2011. Desde logo, agradeço a Pedro Alves a sua cuidadosa tradução. Quero também agradecer a Pedro Alves e a Carlos Morujão pelos comentários e discussões durante esse seminário e ao Conseil de recherches en sciences humaines, do Canadá, pelo seu apoio financeiro.

${ }^{1}$ Utilizo aqui a abreviatura Psychologie em referência à tradução francesa Psychologie d'un point de vue empirique, de Brentano, e Schriften para a edição dos seus escritos pela editora Ontos (ver a bibliografia).
} 
de consciência de si pré-reflexiva. As apreciações estão também divididas quanto ao valor da contribuição de Brentano, a qual se mede, regra geral, pela bitola da sua capacidade para resolver aquilo que se designa, na filosofia da mente, como o "problema da consciência". 2

O meu objetivo neste estudo não é tanto discutir os detalhes e as implicações desta problemática contemporânea em torno de Brentano, mas rever os seus textos principais sobre a consciência, na perspetiva das duas teses que ele formula sobre a consciência logo no início do segundo capítulo do segundo livro da sua Psicologia. Nas três primeiras secções deste estudo, proponho uma análise destas duas teses, prestando uma atenção particular à relação que Brentano estabelece entre consciência e intencionalidade. Examinarei, de seguida, a sua teoria dos objetos primários e dos objetos secundários, pela qual ele articula as suas duas teses sobre a consciência. Nas secções quinta e sexta, examino dois problemas que a teoria da consciência de Brentano levanta, a saber, o problema da regressão e o problema da complexidade, que ele procura resolver com a ajuda do seu princípio da unidade da consciência. Na última parte, inclinar-me-ei sobre alguns textos de Brentano publicados a título póstumo, nos quais faz intervir a noção de agente psíquico (psychich Tätige) nas suas asserções sobre a consciência, e tentarei mostrar que a tomada em linha de conta do agente, nos seus escritos, visa solucionar certos problemas deixados em suspenso na sua $P$ sicologia.

\section{Formulação de duas teses sobre a consciência}

No início do segundo capítulo do segundo livro da sua Psicologia (§ 2), Brentano avança duas teses gerais sobre a consciência, as quais ele formula do seguinte modo:

1. Todo fenómeno psíquico é consciência (Bewußtsein);

2. Todo fenómeno psíquico é consciente (bewußt).

A primeira tese utiliza a consciência no seu sentido transitivo, isto é, enquanto consciência de qualquer coisa; ela é, portanto, neste sentido, consciência intencional. Proponho reformulá-la do seguinte modo:

1b. Todo fenómeno psíquico é consciência de qualquer coisa.

Numa primeira aproximação, a noção de consciência, na segunda tese, está empregue num sentido intransitivo, enquanto predicado monádico ${ }^{2}$ Discuto a interpretação da teoria da consciência de Brentano na perspetiva das teorias de
ordem superior da consciência em Fisette (2013). 
designando uma propriedade intrínseca e não-relacional de um estado mental (o facto, para um estado como a dor, de estar ou não consciente). Mas esta interpretação está em contradição com a formulação da primeira tese, pois a consciência não pode ser, ao mesmo tempo, transitiva, como o pretende a primeira tese, e intransitiva, no sentido desta interpretação da segunda tese. Uma outra interpretação, inspirada pelo uso que Brentano faz da noção de inconsciente na sua Psicologia (Schriften I, p. 120), repousa na distinção entre o sentido passivo e o sentido activo desta noção. A noção de consciência, tal como compreendida na segunda tese, é comparável ao sentido que Brentano atribui à noção de inconsciente, que utiliza num sentido passivo, isto é, no sentido em que "inconsciente" se diz de uma coisa de que (não) temos consciência, recusando Brentano admitir o bem-fundado do sentido ativo da noção de inconsciente (Schriften I, p. 120). No seu sentido passivo, portanto, a consciência designa o fenómeno mental de que temos consciência ou enquanto ele é "objeto de consciência", como o quer também Brentano. Para retomar o exemplo de Brentano, diremos que, na audição de um som, o fenómeno mental da audição é, no seu sentido ativo, a propósito do som, ao passo que o ato de audição, no seu sentido passivo, é ele próprio objeto de consciência no sentido em que, como o mostraremos mais tarde, o agente está consciente de estar nesse estado. Podemos, então, reformular a segunda tese de Brentano à luz desta interpretação fundada na distinção entre o sentido passivo e o sentido ativo do termo "consciência":

2b. Todo fenómeno psíquico é objeto de consciência.

Esta nova formulação encaixa-se na teria dos objetos primários e secundários, pela qual Brentano articula as suas duas teses sobre a consciência e na qual os fenómenos mentais são, simultaneamente, a propósito de um objeto primário (o som ouvido) e a propósito de si próprios, enquanto "objetos" secundários (a audição do som). É à segunda tese que Brentano consagra a maior parte da sua discussão sobre a consciência no segundo livro da sua $P_{s i-}$ cologia, e é esta tese que ele opõe, desde o início, à hipótese de estados mentais inconscientes (Schriften I, p. 119).

\section{Consciência e intencionalidade}

No início do terceiro capítulo da sua Psicologia, Brentano toma por adquirido que a primeira tese (Schriften I, p. 119) foi já estabelecida no capítulo precedente, cujo tema geral era a distinção entre duas classes de fenómenos. É para fins desta classificação que ele introduz, nesse capítulo, o seu conceito de intencionalidade, que concebe, ao mesmo tempo, como um dos cri- 
térios desta classificação e como um traço característico dos estados mentais. Mas porque Brentano não trata explicitamente da relação entre consciência e intencionalidade neste primeiro capítulo, a sua observação acerca do sentido que toma a consciência na primeira tese (enquanto consciência de...) parece indicar que uma das propriedades essenciais da consciência corresponde a um dos traços característicos da intencionalidade na famosa definição que propõe no primeiro capítulo, a saber, que todo e qualquer fenómeno psíquico é a propósito de um objeto (Richtung auf ein Objekt, Schriften I, p. 109). É isso que Brentano parece confirmar quando afirma que as noções de consciência (no sentido ativo) e de intencionalidade são sinónimas, na medida em que designam esta propriedade de um estado mental de ser a propósito de um objeto intencional (Schriften I, p. 119).

Além disso, o termo consciência, aplicando-se a um objeto de que a consciência é consciência, parece ser de todo apropriado para caracterizar os fenómenos psíquicos, precisamente a partir da sua diferença específica, isto é, da propriedade de inexistência intencional de um objeto, fenómeno para o qual carecemos igualmente de um nome usual. (Psychologie, p. 114; Schriften I, p. 119)

Reencontramos observações similares noutros textos pertencentes ao período vienense, nomeadamente, nas suas lições sobre psicologia descritiva, nas quais sustenta que consciência e intencionalidade têm a mesma extensão, ou seja, que não há consciência sem intencionalidade e vice-versa (Brentano, 1982: 26). Mencionemos, por fim, um passo da sua conferência de 1889 sobre ética, no qual Brentano deplora a equivocidade da noção de consciência e a define, de novo, pela noção de intencionalidade, que ele concebe, desta vez, como uma relação:

O traço característico comum a tudo o que é psíquico é constituído pelo que muitas vezes se definiu utilizando um termo que, infelizmente, muito se presta a mal-entendidos: a consciência, ou seja, um comportamento do sujeito, uma relação que se qualificou como intencional a qualquer coisa que não é, talvez, efetivamente dada, mas que, no entanto, está interiormente presente de maneira objetiva. (Brentano, 2003: 48-49; cf. 1982: 23)

A noção de relação intencional vem precisar o sentido da direcionalidade na definição de intencionalidade que ele propõe na Psicologia. Nas suas lições sobre a psicologia descritiva, Brentano atribui-lhe duas propriedades essenciais, das quais a primeira reenvia para a noção de correlação: "como em toda relação, reencontramos aqui dois correlatos. Um dos correlatos é o ato de consciência, o outro, aquilo para que ela está dirigida" (Brentano, 1982: 23). ${ }^{3}$

${ }^{3}$ Comparar com este passo de $A$ Origem do Conhecimento Moral: "Não há audição sem qualquer coisa que seja ouvida, não há crença sem qualquer coisa a que dar crédito, não há espe- 
A segunda propriedade está ligada ao estatuto ontológico de um dos termos da relação, ou seja,

Que só um é real, ao passo que o outro não é qualquer coisa real (nichts Reales). Um homem pensado é qualquer coisa tão real como uma pessoa que deixou de existir (gewesener Mensch). (Brentano, 1982: 24)

Este segundo traço corresponde ao uso que Brentano faz do termo "inexistência intencional" na sua Psicologia.

Reencontramos, portanto, nesta definição parcial da consciência, os traços característicos principais que Brentano atribui aos fenómenos mentais na sua definição de intencionalidade: relação com um objeto intencional ou, como o quer também uma outra definição da consciência, um "modo particular de imanência do objeto à mente" (Psychologie, p. 239). De acordo com esta definição, a tese segundo a qual todo e qualquer fenómeno psíquico é consciência (de qualquer coisa) parece confundir-se com a caracterização dos estados mentais enquanto fenómenos que mantêm uma relação intencional com qualquer coisa outra que eles próprios e, no caso vertente, com objetos intencionais. ${ }^{4}$

\section{Três modos de consciência}

Todos os fenómenos mentais estão conscientes ou, como também o diz Brentano, esta classe de fenómenos é sempre acompanhada por uma consciência correlativa. Por vezes, Brentano designa esta consciência concomitante pela noção de perceção interna, que opõe, na Psicologia, à perceção externa, que designa unicamente a classe dos atos psíquicos que têm por objeto fenómenos físicos como o som ou a cor, por exemplo. A noção de consciência, tal como é empregue na segunda tese, designa, assim, a perceção interna, que representa, para a psicologia descritiva, uma via privilegiada de acesso aos fenómenos mentais (Psychologie, p. 48, 104). Ela está limitada aos fenómenos psíquicos, na medida em que estes são os únicos que, falando propria-

rança sem qualquer coisa que seja esperada, não há esforço sem qualquer coisa para que se tenda, não há alegria sem qualquer coisa de que nos alegremos, e assim sucessivamente." (Brentano, 2003: 49).

${ }^{4}$ Brentano define igualmente a consciência com a ajuda da noção de conteúdo. Com efeito, logo no início do terceiro capítulo do segundo livro, Brentano diz da consciência que ela designa "todo e qualquer fenómeno psíquico porquanto tenha um conteúdo" (Psychologie, p. 147). Recordemos que a noção de conteúdo representa, juntamente com as de inexistência intencional e de direccionalidade, uma das três noções pelas quais Brentano define a intencionalidade na sua Psicologia (Psychologie, p. 102). 
mente, podem ser internamente percecionados. A perceção interna preenche, assim, uma função epistémica na filosofia de Brentano. Ela distingue-se da perceção externa por ser, como em Descartes, imediatamente evidente, e constitui a fonte primeira do nosso conhecimento dos fenómenos mentais. Mas esta função epistémica não é senão uma das duas funções que a consciência interna preenche, ${ }^{5}$ sendo a outra a sua função psicológica. A sua função epistémica está estreitamente ligada à evidência da perceção interna, e consiste na justificação do juízo. Na sua função psicológica, ao invés, a consciência interna designa o modo de acesso privilegiado do agente aos seus próprios estados mentais, sendo neste sentido que Brentano diz da perceção interna que ela é o modo privilegiado pelo qual tomamos consciência dos nossos próprios estados mentais. Na sua função psicológica, a consciência interna tem, portanto, mais extensão do que na sua função epistémica, porque se aplica, indiferentemente, a todas as classes de estados mentais, ou seja, às representações, aos juízos e aos sentimentos, ao passo que, na sua função epistémica, a perceção interna está limitada à classe dos juízos. Para as necessidades do presente estudo, insistiremos sobretudo no sentido psicológico da perceção interna, compreendida como consciência interior.

Uma outra noção importante na Psicologia, pela qual Brentano estabelece a relação entre a consciência e os estados mentais, é a noção de modo de consciência. Logo no início do terceiro capítulo do segundo livro da sua Psicologia, depois de ter estabelecido que todo e qualquer ato psíquico é acompanhado por uma consciência concomitante, ou seja, que, na audição de um som, por exemplo, a representação do som está sempre acompanhada por uma consciência dela própria, Brentano afirma que os fenómenos psíquicos designam os modos pelos quais a consciência entra em relação com os seus objetos (Psychologie, p. 147; Schriften I, p. 157). Brentano (Schriften III, p. 39) compara a noção de modo de consciência com o que Helmholtz (1879, p. 9) chama, no seu texto clássico Die Tatsachen in der Wharnehmung, as modalidades das sensações, pelas quais designa, ao mesmo tempo, as diferenças específicas entre as classes de qualidades sensíveis (tais como cor, som, etc.) e as sensações pertencentes a sentidos diferentes, como, por exemplo, “o azul, o doce, o quente".

De acordo com esta analogia, os modos de consciência estariam para as classes de fenómenos psíquicos como as modalidades de sensações estão para as diferentes classes de qualidades sensíveis. E, com efeito, toda a classifi-

\footnotetext{
${ }^{5}$ Numa nota logo no início do capítulo II, Brentano distingue explicitamente consciência interior e perceção interna: "Do mesmo modo que se chama perceção «interna" à perceção de uma atividade psiquica atualmente presente em nós, chamamos aqui consciência «interior» a consciência que se the reporta" (Psychologie, p. 113; Schriften I, p. 118).
} 
cação dos fenómenos psíquicos na sua Psicologia está fundada sobe os três modos gerais pelos quais a consciência se refere aos seus objetos: ${ }^{6}$

Quando nós dizemos que a representação e o juízo constituem duas classes fundamentais distintas de fenómenos psíquicos, isso significa, de acordo com o precedente, que eles correspondem a dois modos absolutamente diferentes da consciência que tomamos de um objeto. (Psychologie, p. 207)

Brentano distingue três modos pelos quais se toma consciência de um objeto: o modo representacional, o modo judicativo e o modo do sentimento. O modo de relação com o objeto que inclui unicamente uma representação é o mais pobre; consiste somente no facto de que o objeto está presente para a consciência e se the manifesta. Trata-se, então, de um modo de consciência passivo, em oposição aos dois outros modos, que pressupõem tomadas de posição ativas da consciência a respeito dos seus objetos. Estes últimos modos caracterizam-se pela oposição, no seio da relação intencional do juízo e das emoções com os seus objetos, entre a aquiescência e a rejeição, no caso do juízo, e entre o amor e o ódio, no caso das emoções. É neste sentido que se deverá compreender o sentido da tese da perceção (interna) como um juízo, ou seja, como uma tomada de posição e como aquiescência ou rejeição do objeto julgado.

Esta definição dos fenómenos psíquicos como modos de consciência levanta, de novo, a questão acerca da relação entre consciência e intencionalidade que tínhamos evocado no nosso exame da tese de Brentano sobre a consciência. Várias passagens da obra de Brentano que citámos em apoio da primeira tese pareciam indicar que os termos "consciência" e "intencionalidade" são permutáveis, e mesmo que ele se inclina para uma conceção intencionalista da consciência. No entanto, ao conceber os estados intencionais como modos de consciência, Brentano sugere, além disso, que não só consciência e intencionalidade não são permutáveis, mas que é a intencionalidade, compreendida como relação com um objeto intencional, que está subordinada à consciência, na medida em que ela designa os modos pelos quais a consciência entra em relação com os seus objetos. Trata-se, aqui, do estatuto desta consciência concomitante, a propósito da qual Brentano repete, em vários lugares na sua $P$ sicologia, que acompanha todos os atos, como o pretende uma das interpretações da sua segunda tese sobre a consciência.

A este respeito, há pelo menos duas maneiras de compreender o que Brentano entende por modo de consciência: num sentido psicológico e num sentido ontológico. O sentido psicológico ressalta claramente no uso que

${ }^{6}$ Cf. Brentano, Schriften I, p. 218; 2003, p. 49; Schriften III, p. 39. 
Brentano faz desta noção em relação com a classificação dos atos. Designa, como acabámos de o ver, as qualidades dos atos, sobre que se apoia a sua classificação, e os modos pelos quais a consciência está em relação com os seus objetos. Ao invés, no seu sentido ontológico, esta noção designa os atributos ou os momentos de um substrato, e ela corresponde ao que Brentano chama, na sua metafísica, uma "parte metafísica". Na sua Psicologia, Brentano utiliza de preferência a noção de Divisiv, pela qual, como o veremos mais tarde, caracteriza os fenómenos mentais como partes ou atributos de um fenómeno unitário complexo. A sua teoria da unidade da consciência, que examinaremos igualmente mais tarde, parece confirmar que, na multiplicidade dos fenómenos mentais que entra em linha de conta mesmo na consumação dos atos mais simples, esses fenómenos constituem momentos ou modos da consciência unitária e real.

\section{Consciência in recto e in obliquo}

Como pode a consciência estar simultaneamente em relação com um fenómeno físico (tese 1) e consigo própria enquanto objeto (tese 2)? A resposta de Brentano repousa sobre a sua teoria dos objetos primários e secundários e sobre a distinção aristotélica entre os modos de relação in recto e in obliquo. Partamos desta formulação geral de Brentano:

Podemos dizer que o som é o objeto primeiro da audição, e que a audição é o objecto segundo. No tempo, apresentam-se ambos em simultâneo, mas, segundo a natureza das coisas, o som é anterior à audição. [...] A audição aparece, no sentido mais próprio da palavra, voltada para o som (dem Ton zugewandt), e, por esse mesmo facto, parece perceber-se de passagem (nebenbei) e a título suplementar (als Zugabe). (Psychologie, pp. 137-138; Schriften I, p. 146)

Esta formulação presta-se a confusão, porque os termos nebenbei (de passagem) e sobretudo Zugabe (extra) sugerem que a consciência que acompanha a representação do som é extrínseca à audição e não constitui senão um simples aditivo, como a nata ou o açúcar que se junta ao café, sendo-lhe, neste sentido, imposta do exterior, como na teoria dos pensamentos de ordem superior, onde o conteúdo do estado de ordem superior torna consciente o estado que tem como alvo.

Há várias maneiras de compreender esta dupla relação que a consciência mantém com os seus objetos primários e os seus objetos secundários, das quais a mais comum é a distinção lógica entre aquilo que um termo denota e aquilo que ele conota. Mas, no contexto psicológico que nos importa aqui, a distinção entre consciência focal e consciência periférica (ou ainda a noção de cons- 
ciência marginal em Gurwitsch e a noção de franja em W. James) são mais adequadas para dar conta desta dupla relação in recto e in obliquo, sendo usada, em geral, a fim de explicar a diferença entre a consciência que temos das coisas sobre as quais fazemos incidir diretamente a nossa atenção e a consciência que temos das coisas que fazemos de modo irrefletido ou que percebemos sem prestar atenção. Neste sentido, a consciência in recto do objeto primário corresponderia à consciência focal do som, ao passo que a consciência in obliquo que acompanha a audição do som corresponderia à consciência periférica da audição.

Nas suas lições vienenses sobre a psicologia descritiva, Brentano acrescenta um complemento de informação às análises da sua Psicologia sobre a consciência e introduz certas distinções que parecem militar a favor desta última interpretação. ${ }^{7}$ Penso, em particular, na distinção entre consciência implícita (ou consciência no sentido lato) e consciência explícita (ou consciência em sentido estrito), a qual está, nas suas lições, estreitamente associada à noção central de "notar algo" (Bemerken). Brentano aplica-a, desde logo, à perceção externa de um objeto primário e sublinha que podemos ver ou discernir (implicitamente) o que não apercebemos (explicitamente). É o que mostra o seguinte exemplo, que relembra os casos utilizados por Dretske (1993) na sua crítica de Rosenthal:

Quem vê a cotovia no azul do céu não a nota ainda, no entanto, e não nota, ainda menos, que vê a cotovia, mesmo que o facto de ver a cotovia seja vivido (mitempfinden) por ele de maneira concomitante. Todavia, se, num momento dado, ele não somente visse a cotovia mas também a notasse, então ele notaria simultaneamente que a vê. [...] Ver é diferente de [perceber] claramente o que é visto. É assim que a experiência concomitante (mitempfinden) do ver será diferente da [perceção] clara desse ver, de que fazemos experiência de maneira concomitante. (Brentano, 1982: 23-24)

Brentano pressupõe que a cotovia não é o objeto explícito deste ato, se bem que ela esteja no seu campo visual e esteja consciente de maneira implícita. O que é o mesmo que dizer que um estado pode estar implicitamente consciente sem que o sujeito esteja dele explicitamente consciente. É o que também mostra o caso bem conhecido do condutor desatento de D. Armstrong (1997: 723), que se utiliza frequentemente na literatura, como exemplo em uso pelas teorias de ordem superior da noção de inconsciente. Brentano diria desse condutor não que ele é inconsciente, como o querem os defensores das teorias de ordem superior da consciência, mas sim que ele tem, então,

${ }^{7}$ Cf. o artigo de K. Mulligan, "Brentano on the Mind" para uma análise destas distinções nas lições de Brentano sobre psicognosia. 
uma consciência implícita e periférica de conduzir o seu veículo. Pois não só Brentano não admite estados mentais inconscientes, como sustenta, além disso, que o agente não pode estar explicitamente consciente de ter experiência de qualquer coisa (como uma cotovia, por exemplo) senão na condição de estar disso implicitamente consciente (Brentano, 1982: 34). A consciência explícita, ou consciência em sentido estrito, corresponde ao que Brentano chama, nas suas lições, o ato de notar (Bemerken), que concebe como a perceção explícita daquilo que está implicitamente contido na consciência (Ibid., 36). Esta distinção entre consciência implícita e consciência explícita permite dissipar certas obscuridades da sua teoria inicial, no que diz respeito, nomeadamente, ao estatuto dos fenómenos físicos na sua Psicologia, como o sublinhou Husserl na sua crítica de Brentano nas Investigações Lógicas. ${ }^{8}$

A questão consiste em saber se a distinção entre consciência implícita e consciência explícita suporta a nossa interpretação da teoria de Brentano acerca da teoria da consciência in recto e in obliquo em termos de consciência periférica e de consciência focal. Ela aplica-se, em primeiro lugar, aos objetos da perceção externa, na medida em que a consciência implícita corresponde à consciência in obliquo da cotovia, por oposição à consciência focal do céu azul, para retomar o exemplo de Brentano. Mas, no passo citado no início desta secção, Brentano associa a relação in recto ao objeto primário (Tese 1) e a relação in obliquo ao objeto secundário, quer dizer, à consciência da representação do objeto primário (Tese 2). Neste sentido, a consciência focal estaria para a relação com o objeto primário como a consciência periférica (implícita ou em sentido alargado) estaria para a relação indireta com o objeto secundário. Com a diferença, todavia, de que a perceção interna, compreendida como consciência explícita, tem como objeto o ato psíquico integral, que inclui o objeto primário e o objeto secundário.

\section{Objeções contra a segunda tese}

Examinemos agora algumas objeções que a segunda tese geral sobre a consciência suscita, objeções que Brentano examina no segundo livro da sua Psicologia. Duas dessas objeções remontam a Aristóteles, sendo mais bem conhecidas sob os nomes de "regressão ao infinito", que Brentano examina em relação com o postulado dos fenómenos mentais inconscientes, e de "duplicação", segundo a qual o fenómeno psíquico seria representado duas

${ }^{8}$ Cf. D. Fisette (2010) para um exame da critica que Husserl faz a Brentano nas suas Investigações Lógicas, e A. Werner (1931) sobre o estatuto ambíguo da noção de fenómeno fisico na
Psicologia de Brentano. 
vezes, uma primeira vez na representação do som e uma segunda vez na representação da representação do som. Interesso-me muito particularmente pela objeção de regressão ao infinito, que Brentano examina na secção 7 (Psychologie, pp. 132 ss.), em ligação com a sua segunda tese sobre a consciência, objeção de acordo com a qual esta tese ficaria exposta a uma regressão ao infinito. Pois, quando se nega que a representação que acompanha a audição do som seja inconsciente, como o querem a maior parte das teorias de ordem superior da consciência, parece que seremos, então, forçados a admitir um número infinito de fenómenos psíquicos.

Comecemos por enunciar o problema da regressão com ajuda da formulação que Brentano apresenta na sua Psicologia:

Tal como não importa que outro fenómeno psíquico, a representação da audição do som e também a do som devem ser apresentadas de modo consciente; é necessário, portanto, que haja disso igualmente uma representação. No sujeito que ouve, teremos, portanto, três representações, a do som, a da audição e a da representação da audição. Mas esta terceira representação não pode ser a última. Também ela está consciente, portanto, é representada, e a representação que se lhe refere é, por sua vez, representada; numa palavra, ou bem a série é infinita, ou bem que ela termina numa representação inconsciente. Por conseguinte, quando se nega a existência de fenómenos psíquicos inconscientes, é-se obrigado, no mais simples ato de audição, a admitir uma massa infinita de atividades psíquicas. (Pychologie, pp. 132-133)

Podemos reformular esta objeção de maneira esquemática pondo o acento tónico nas duas teses de Brentano sobre a consciência que estão implícitas na formulação deste problema da regressão:

1. Todo fenómeno psíquico é a propósito de um objeto (audição do som) (Tese 1).

2. Todo fenómeno psíquico é ele próprio objeto de uma consciência concomitante (representação da audição do som) (Tese 2).

3. A representação que acompanha o estado mental inicial é um ato psíquico numericamente distinto do ato mental alvo.

4. Mas se a representação da audição deve ela também estar consciente (Tese 2), e se a representação que a torna consciente deve, por seu turno, estar consciente, a série será, então, infinita.

5. Por conseguinte, ou bem a representação do estado inicial é inconsciente (e a Tese 2 é falsa), ou bem o número de atos é infinito.

A solução que Brentano propõe para o problema da regressão, bem como para o da duplicação, consiste em rejeitar, num primeiro tempo, uma das premissas comuns a estas duas objeções, a saber, que a consciência concomitante que acompanha a representação do som seja um ato numericamente distinto 
desta última. Brentano sustenta que a representação do som e a representação da representação do som não são senão um e mesmo ato, que incide sobre dois objetos, um objeto primário e um objeto secundário. Nesta perspectiva, esta distinção entre dois atos, um ato de nível inferior e um ato de nível superior, não é, em definitivo, mais do que uma simples abstração conceptual:

A representação do som e a representação da representação do som não fazem mais do que um só fenómeno psíquico, que nós, de modo abstrato, decompusemos em duas representações, ao considerá-lo na sua relação com dois objetos diferentes, dos quais um é um fenómeno físico e o outro um fenómeno psíquico. (Psychologie, p. 137; Schriften I, p. 146)

Dito de outro modo, não são duas entidades numericamente distintas, mas sim dois abstracta que fazem parte de uma só e mesma coisa, como, por exemplo, a forma e a grandeza de um círculo ou ainda a velocidade e a direção do movimento. ${ }^{9}$ A questão é, evidentemente, saber o que Brentano entende exatamente quando diz que a representação do som e a representação da representação do som designam uma só coisa.

A segunda pressuposição que Brentano ataca na sua resposta é mais específica do argumento da regressão ao infinito, e ela repousa sobre a ideia de que a consciência concomitante toma por objeto a representação inicial, como numa teoria de ordem superior da consciência, onde o pensamento de ordem superior tem o estado alvo como único objeto. Brentano responde pela sua teoria dos objetos primários e secundários, que, como o vimos, pretende que 0 objeto secundário da consciência concomitante não seja unicamente a representação inicial ou estado alvo, mas sim $o$ ato psíquico por inteiro, no qual o som é representado enquanto objeto primeiro e ela própria é dada a título de objeto segundo (cf. Brentano, Psychologie, p. 139; Schriften I, p. 148). A chave da solução de Brentano tanto para o problema da regressão (Psychologie, p. 142) como para o da duplicação reside na ideia de um emaranhamento peculiar (eigentümliche Verwebung) da representação do objeto primário com a representação de ordem superior, como o explica em resposta à objeção da duplicação:

A experiência interior parece provar, antes, de modo incontestável, que a representação do som está ligada intimamente à representação da representação do som, que, pelo próprio facto da sua existência, ela contribui, ao mesmo tempo, interiormente, para a existência da outra. Este facto leva a crer que existe um

\footnotetext{
${ }^{9}$ Como o explica Brentano em religion und Philosophie, „Es ist ein Akt, den wir nur begriffich zerlegen, indem wir ihn einerseits denken, insofern er das Farbige, andererseits insofern er das Farbiges-Sehende zum Objekt hat, ähnlich wie wir an einem Kreis Gestalt und Größe oder an einer Bewegung Richtung und Geschwindigkeit unterscheiden" (Brentano, 1954: 191).
} 
emaranhamento peculiar (eigentümliche Verwebung) entre o objeto da representação interior e esta representação ela própria, e que eles pertencem ambos a um só e mesmo ato psíquico. E teremos bem de o admitir. (Psychologie, p. 137; Schriften I, p. 146)

A questão será saber em que consiste este emaranhamento peculiar entre o objeto primário e o objeto secundário, pelo qual Brentano procura dar conta da sua pertença a "um só e mesmo ato psíquico". Antes de nos debruçarmos sobre esta questão, podemos concluir o nosso exame das objeções contra a segunda tese dizendo que, de um lado, não há e não poderá haver representação inconsciente no domínio da nossa experiência (Schriften I, p. 122), se bem que a noção de consciência implícita examinada na secção precedente preencha a mesma função; por outro lado, a objeção da regressão, tanto como a da duplicação, não é um argumento contra a teoria de Brentano, porque a série de atos termina com o segundo termo (cf. Psychologie, pp. 139-140; Schriften I, p. 148).

\section{O problema da complexidade e a unidade de consciência}

Quereria, agora, debruçar-me sobre um outro problema que a teoria dos objetos primários e secundários levanta, problema a que chamarei, para os fins deste estudo, "problema da complexidade". Este problema diz respeito à coesão, no seio da consciência interna, entre os elementos que estão implicados na consumação da vida psíquica. É em resposta a este problema que Brentano evoca o princípio da unidade da consciência. Um passo retirado do capítulo II do segundo livro da sua Psicologia, no qual Brentano resume os resultados da sua pesquisa, constitui também uma boa exposição do problema da complexidade:

Todo ato psíquico, mesmo o mais simples, pode, portanto, ser considerado sob quatro aspectos diferentes: desde logo, como representação do seu objeto primário [...]; depois, como representação de si próprio; como conhecimento de si próprio; como sentimento de si próprio. E, no conjunto destas quatro relações, ele constitui, em conjunto, o objeto da representação de si mesmo e o objeto do conhecimento de si mesmo, e também, por assim dizer, do sentimento de si mesmo, do mesmo modo que, sem que seja necessário uma nova complicação, nem uma nova multiplicação, a representação de si mesmo é representada, o conhecimento de si mesmo representado ao mesmo tempo que conhecido, e o sentimento de si mesmo representado, bem como conhecido e sentido. (Psychologie, p. 162; Schriften I, p. 174)

Ponho entre parênteses o modo emocional, porque Brentano concede-lhe um estatuto à parte depois da publicação da sua Psicologia, como o sublinha 
no apêndice à classificação dos atos, no qual indica que este modo não está implicado em todos os atos (Psychologie, p. 270). Limitar-me-ei, portanto, no que se segue, aos modos representacional e judicativo.

A primeira questão que Brentano põe consiste em saber se a multiplicidade destes elementos forma um todo ou um coletivo (Kollektiv), que define da seguinte maneira:

Um coletivo é uma multiplicidade de partes agrupadas (zusammengefaßt) sob um mesmo ponto de vista, das quais cada uma é uma coisa independente. (Bren-
tano, 1954: 225)

Contrariamente a um simples agregado, um coletivo pode ser apreendido de um ponto de vista unitário e forma um conjunto unitário, como o explica Brentano neste passo. No entanto, contrariamente ao todo, as suas partes, ou mais precisamente os seus pedaços (Stücke), mantêm entre si uma relação de independência com o coletivo de que fazem parte, no sentido de que a-sua existência não depende da sua participação no conjunto. Outra coisa se passa com um todo como uma melodia, por exemplo, cujas partes são momentos ou aquilo a que chama também, na Psicologia, "divisivos", ${ }^{10}$ que, ao contrário das partes de um coletivo, mantêm com o todo de que são partes relações de dependência. Podemos, portanto, reformular a questão inicial perguntando-nos se a multiplicidade dos estados que são interiormente percebidos se apresenta ou como um coletivo ou como um todo:

Quando se trata de estados psíquicos complicados (verwickelten), estamos perante um coletivo de coisas? Ou antes, tanto nos estados mais complicados como nos estados mais simples, a totalidade dos fenómenos psíquicos pertence a uma só e mesma realidade, na qual nós não podemos distinguir senão divisivos enquanto partes? (Psychologie, p. 165; Schriften I, p. 176).

Podemos desde já responder a esta questão fazendo ver que a própria ideia de um colectivo vai contra alguns dos princípios fundamentais da psicologia de Brentano, tais como o do caráter fundante da representação e o da dependência do juízo e do sentimento relativamente à representação. Também não é compatível com a teoria dos objetos primários e dos objetos secundários, porque esta pressupõe uma dependência biunívoca da consciência primária e

\footnotetext{
${ }^{10}$ Brentano justifica o uso do neologismo "divisivo" (Divisiv) no seguinte passo: "Do mesmo modo que atribuímos um só e único nome a uma reunião de várias coisas, podemos considerar e designar cada parte de uma coisa como uma coisa à parte. Mas do mesmo modo que, no primeiro caso, a designação se aplicava não a uma coisa, mas a um coletivo, a denominação não se aplicará também aqui a uma coisa e, à falta de um vocábulo usual e claro, dado que o nome 'parte' se aplica igualmente a coisas efetivas em relação aos coletivos, empregaremos o termo 'divisivo"' (Psychologie, p. 165; Schriften I, p. 176).
} 
da consciência secundária. ${ }^{11}$ A complexidade que toda e qualquer actividade psíquica pressupõe constitui, ao contrário, um todo cujos estados mentais são os divisivos. A este título, a consciência do objeto primário e a consciência do objeto secundário são partes metafísicas de um só e mesmo fenómeno unitário e de uma única realidade. Donde o princípio da unidade da consciência, pelo qual Brentano procura dar conta da pertença comum do conjunto destes elementos a uma única realidade (Psychologie, p. 169).

O princípio da unidade da consciência é invocado desde o primeiro livro capítulo do livro II da Psicologia, em resposta à questão de saber por que razão os múltiplos fenómenos mentais que estão implicados nos atos mais simples aparecem à consciência não como um agregado de elementos dispersos, mas sim como uma realidade unitária. É neste contexto que Brentano se socorre da sua teoria dos todos e das partes e que concebe os fenómenos mentais como "fenómenos parciais" (Teilphänomene) de um fenómeno unitário, no qual eles estão contidos como uma só coisa unitária" (Psychologie, p. 110; Schriften I, p. 114). Este princípio está pressuposto em cada uma das etapas da elaboração da sua teoria da consciência nos capítulos subsequentes do segundo livro da Psicologia. Ele impõe-se claramente em resposta ao problema da complexidade, que deriva da teoria dos objetos primários e secundários; e vimos que o problema da regressão, assim como o da duplicação, é insolúvel a menos que se pressuponha que os objetos primários e secundários formam um todo unitário insecável. É o que afirma, aliás, Brentano no termo da sua reflexão sobre a unidade de consciência:

[O] conjunto (Gesammtheit) do nosso estado psíquico, qualquer que seja a complexidade, constitui sempre uma realidade. É o facto bem conhecido da unidade da consciência, que, com razão, se considera, em geral, como um dos princípios (Punkte) mais importantes da psicologia. (Psychologie, p. 171; Schriften I, p. 182)

Este princípio não visa, portanto, eliminar a complexidade em prol da simplicidade, mas visa garantir que o que é percebido na consciência interna é, apesar dessa complexidade, qualquer coisa unitária.

\footnotetext{
${ }^{11}$ A este respeito, recordemos que Brentano distingue nitidamente a relação hierárquica entre as três classes de atos da relação entre os objetos primários e os secundários. Pois, no primeiro caso, a relação de fundação entre a primeira classe e as duas outras traduz-se numa dependência unilateral (einseitig) do juizo e das emoções relativamente à classe das representações, a qual, como o vimos, é em princípio autónoma em relação às outras classes de atos. Ao invés, entre a consciência do objeto primário e a consciência do objeto secundário existe uma relação de dependência biunívoca (gegenseitig), no sentido de que os dois relata são mutuamente dependentes, como o pressupõem, além disso, as duas teses gerais sobre a consciência (cf. Brentano, 1954: 226-227).
} 
Isto dito, tudo o que dissemos até o momento a propósito desta unidade não diz, em definitivo, respeito senão às relações mereológicas de dependência a que Brentano recorre na sua solução metafísica do problema da complexidade. Este aspeto da sua teoria da unidade da consciência dá conta da pertença comum dos elementos a uma só e mesma realidade e não tange, no fim de contas, senão o objeto percebido interiormente. Mas trata-se, aparentemente, apenas de uma das condições que Brentano impõe à unidade da consciência, sendo a outra a condição de simultaneidade, que se aplica, desta vez, à consciência interna enquanto tal:

A unidade da consciência, tal como ressalta com evidência daquilo que percebemos interiormente, consiste nisto: todos os fenómenos psíquicos que se encontram ao mesmo tempo (gleichzeitig) em nós-por mais diferentes que sejam: visão, audição, representação, juízo e raciocínio, amor e ódio, desejo, aversão, etc.--, sob a única condição de serem interiormente percebidos como simultâneos (wenn sie nur als zusammenbestehend innerlich wahrgenommen werden), pertencem todos a uma mesma realidade (sämmtlich zu einer einheitlichen Realität gehören); sendo fenómenos parciais, formam um fenómeno psíquico cujas partes constitutivas não são coisas distintas nem partes de coisas distintas, mas pertencem a uma unidade real. Tal é a condição necessária, mas suficiente, da unidade de consciência. (Psychologie, p. 171; Schriften I, pp. 182-183)

Pela noção de simultaneidade, Brentano parece querer dar conta do facto de que este fenómeno complexo é um dado imediato e não-inferencial da consciência interna e afastar o factor temporal que está envolvido na consumação dos numerosos atos que menciona nesta passagem, os quais fazem parte desse fenómeno complexo. A condição de simultaneidade pressupõe, além disso, que se tenha consciência da simultaneidade enquanto tal, ou seja, para retomar o caso da melodia que Brentano utiliza amiúde na sua Psicologia ( $c f$. por exemplo Psychologie, p. 168; Schriften I, p. 179), que não só nos representemos vários objetos de cada vez, mas que tenhamos também consciência de que esses objetos pertencem no seu conjunto a uma só e mesma realidade, no caso, à melodia. Neste sentido, a condição de simultaneidade estaria para a consciência do fenómeno unitário como a condição ontológica de pertença a uma única realidade está para o objeto percecionado, quer dizer, para o objeto intencional.

\section{O agente psíquico e a consciência de si}

A hipótese que desenvolverei sucintamente nesta secção é a de que Brentano recorre à noção de agente psíquico ou de "coisa mentalmente ativa" (psychich Tätige) a fim de solucionar dois problemas deixados em suspenso 
na sua Psicologia: o do substrato dos modos de consciência e o da consciência do ato psíquico inteiro, que podemos compreender, desde logo, como a consciência que o agente toma de si mesmo enquanto portador do estado complexo em que se encontra. Os comentadores de Brentano estão divididos sobre a questão de saber o que motiva o recurso à noção de agente psíquico em Brentano. A introdução da noção de agente psíquico coincide e vai a par com uma mudança importante na sua conceção da consciência, mais precisamente na sua interpretação da segunda tese geral sobre a consciência, a qual quer que todo estado psíquico esteja consciente, no sentido de que ele é sempre objeto de uma consciência que o acompanha. ${ }^{12}$ A minha hipótese é que Brentano concebe essa noção, tardiamente, como uma consciência de si, quer dizer, que a consciência do ato psíquico é, de facto, a consciência que o agente toma de si próprio enquanto se encontra nesse estado.

De facto, estes dois problemas estão diretamente ligados às duas significações que nós associámos à noção de modo de consciência, a saber, o sentido ontológico, segundo o qual os estados psíquicos são momentos ou atributos da consciência, e o sentido psicológico, no qual as três classes de ato são modos os pelos quais a consciência entra em relação com os seus objetos. O primeiro problema incide sobre o substrato ou o portador dessas propriedades, ao passo que o segundo diz respeito ao modo pelo qual se toma consciência desse fenómeno unitário complexo. Pois, com efeito, como se poderá tomar consciência deste fenómeno complexo de outro modo que por um qualquer desses modos, mesmo não pressupondo que esse modo constitua ontologicamente um Teilphänomene do fenómeno complexo?

O primeiro problema diz mais precisamente respeito ao que Brentano chama, na sua Psicologia, "este ser unitário real" (Schriften I, p. 175), cujos modos de consciência, enquanto divisivos, são as determinações. Numa primeira aproximação, esta noção designa o estado psíquico integral que forma uma unidade "real" [réelle], no sentido de que todos os fenómenos psíquicos individuais, contrariamente aos fenómenos físicos, "possuem uma existência efetiva fora da existência intencional" (Psychologie, p. 105). E a unidade da consciência, dissemos, não é nada de outro que a pertença dos fenómenos parciais (Teilphänomene) a esta coisa real. Mas o princípio da unidade da consciência, tal como está formulado na Psicologia, não traz consigo precisões acerca da natureza do substrato dos modos de consciência que formam um todo, nem sobre o estatuto da consciência simultânea do conjunto dos elementos que compõem esta unidade. É aqui que intervém o agente psíquico.

${ }^{12}$ Cf. também a introdução de M. Antonelli à sua edição da Psicologia de Brentano (Schriften I, p. LXXX). 
Com efeito, ele responde, desde logo, à questão do substrato real do ato psíquico complexo internamente percecionado, como o confirma Brentano em alguns fragmentos reunidos na obra Religion und Philosophie, no qual formula a sua tese geral em reação ao que designa como o "semimaterialismo" de Aristóteles:

Segue-se, portanto, indubitavelmente que este mesmo sujeito unitário último deve estar no fundamento de todas as atividades psíquicas, sensíveis e não-sensíveis, que caem sob a perceção interna simultânea. A unidade da consciência exclui o semimaterialismo de Aristóteles. (Brentano, 1954: 228)

Assim, os modos de consciência pertencem, decerto, a um só e mesmo ato complexo, como o quer o princípio de unidade da consciência, mas este todo não é a consciência enquanto tal, mas sim o agente psíquico que dela é o portador. Todos os estados conscientes são fenómenos psíquicos que the pertencem no sentido trivial de que é ele, e não outra pessoa, que consuma esses atos e que é ele que está consciente da sua dor no estômago ou do prazer que tem em jogar xadrez ou ao compor poemas. Este acesso privado (ou na primeira pessoa) e privilegiado aos seus próprios estados mentais é, ademais, um pressuposto no uso que Brentano faz da perceção e da consciência internas.

Donde o segundo problema que incide sobre o estatuto da consciência concomitante e a segunda tese geral sobre a consciência na sua $P$ sicologia, segundo a qual todo e qualquer estado psíquico está consciente. Esta tese pode ser interpretada de duas maneiras diferentes, segundo se conceba o predicado "está consciente" como uma propriedade intrínseca aos estados mentais, ou como objeto de consciência, no sentido em que todo ato mental é sempre acompanhado de uma consciência concomitante. A primeira interpretação é problemática, não fosse por mais do que o facto de que um estado mental não estará consciente ou não-consciente a menos que se suponha o que G. Ryle chama o caráter autoluminoso de um estado. ${ }^{13}$ Pois, de facto, um estado necessita de um portador ou um agente que consume os seus atos, e uma explicação da consciência deve ter isso em conta, como, aliás, Brentano o reconheceu (1954: 226-228). A segunda interpretação comporta igualmente o seu lote de problemas, porque ela não explica por que razão o simples facto de estar em relação com um objeto secundário nos torna conscientes de consumar um ato que toma por objeto um fenómeno psíquico. Pois, com efeito, como pode a consciência ser, ao mesmo tempo, consciência (no sentido ativo) desta unidade e objeto de consciência (no sentido passivo), ou seja, ser consciência desta consciência? Brentano encara esta última possibilidade numa discussão com Tomás de Aquino e sustenta que a consciência desta consciência coincide com a consciência da representação inicial. É neste contexto

${ }^{13}$ Cf. D. Rosenthal (1990: 738; 2003: 158-159). 
que Brentano introduz a ideia de que a consciência da consciência do som não é, de facto, nada mais que a consciência do ato psíquico integral, que se torna "no seu objeto e no seu conteúdo próprios" (Psychologie, p. 139). Mas esta consciência concomitante do objeto secundário, compreendida como o ato psíquico integral, não dá razão do facto de que este estado está consciente senão dizendo que nós dele temos consciência. Estas duas explicações da segunda tese que, como já o disse, estão no coração das análises de Brentano sobre a consciência no segundo livro da Psicologia, não dão adequadamente conta, portanto, do que é para um estado mental estar consciente. Brentano parece ter-se apercebido disso tardiamente, e a minha hipótese é que a tomada em linha de conta do agente psíquico visa não somente resolver o problema do substrato dos modos de consciência, mas também fornecer uma explicação mais adequada da segunda tese.

Com efeito, segundo esta explicação, um estado está consciente somente se o agente toma consciência não desse estado enquanto tal, mas sim de si mesmo enquanto se encontra nesse estado. Assim, a tomada em linha de conta do agente psíquico nesta teoria da consciência implica que, na consumação normal de um ato de perceção externa, por exemplo, o agente toma consciência, para lá do objeto primário, também de si mesmo enquanto agente que perceciona (Brentano, 1954: 226). É o que confirma uma passagem do apêndice de 1911 sobre a classificação dos atos, no qual Brentano sustenta que o objeto da consciência secundária ou da perceção interna é o agente psíquico ele próprio, o qual contém, de uma só vez, a relação com o objeto primário da consciência e a consciência secundária da relação consigo próprio:

Como o observei na minha Psicologia do Ponto de Vista Empírico, não se deve tomar como objeto segundo da atividade psíquica uma qualquer dessas relações, por exemplo, a relação com o objeto primário; $[. .$.$] o que constitui o objeto$ segundo é propriamente a atividade psíquica ou, mais exatamente, o agente psíquico que envolve (sondern die psychische Tätigkeit, genauer gesprochen das psychisch Tätige, in welchem beschlossen ist), de uma vez, a relação segunda e a relação primeira. (Psychologie, p. 270; Schriften I, p. 385)

Este passo evidencia um novo modo de consciência que não encontramos na Psicologia, a saber, o modo de consciência de se, que designa a consciência que o agente toma de si próprio enquanto se encontra nesse estado complexo. Para tomar de novo o exemplo da representação do som, a consciência de si assemelhar-se-ia a isto: estou, eu próprio, a representar um som, a ter dele uma experiência. ${ }^{14}$ Este ponto sobressai ainda mais claramente no

${ }^{14}$ Comparar com as observações de Kriegel (2003: 480-481) a propósito da distinção, em Brentano, entre self-representation e representation of the self. 
caso da dor, enquanto estado de que o agente toma necessariamente consciência na primeira pessoa. A tese pretendendo que todo estado psíquico está consciente dever-se-ia, portanto, compreender à luz do modo de consciência de se, como a tese de que esta consciência de si está implícita em toda a experiência. Esta tese encontra uma nova confirmação na distinção, de que se tratou anteriormente, entre consciência implícita (ou consciência no sentido largo) e consciência explícita (consciência no sentido estrito) que Brentano aplica, nas suas lições de psicognosia, tanto à perceção externa como à perceção interna. Vimos que a teoria da consciência, na Psicologia, se limita à consciência interior (ou à consciência implícita). Ora porque os fenómenos físicos não são dados da consciência interna, que se limita aos estados mentais, punha-se a questão de saber se esta classe de fenómenos designa conteúdos da experiência sensível. O recurso à noção de consciência implícita mostra que os qualia são dados da consciência primária e que, contrariamente à conceção que deles se fazem as teorias de ordem superior, a experiência qualitativa (e a consciência implícita, pelo agente, da dimensão sensível) é uma condição necessária para os pensamentos que a tomam por objeto e preexiste-lhes. Notemos, por fim, que esta consciência primária é consciência intransitiva e pré-reflexiva, como o mostram as observações de Breantano sobre Thomas Reid.

Isto dito, tanto a adoção por Brentano da noção de consciência de si mesmo, como a tomada em linha de conta do sujeito da experiência, não põem em questão o bem-fundado da sua teoria dos objetos primários e dos objetos secundários, nem também o lugar que compete, nesta teoria, ao princípio da unidade da consciência. Enquanto substrato real do conjunto dos modos de consciência, o sujeito constitui o lugar da unidade de consciência, mas ele não é o princípio unificador. Vimos que, nos escritos posteriores à Psicologia, a sua teoria da consciência conhece um alargamento, pois que integra o que ele designa, por vezes, a consciência primária ou consciência no sentido largo, que inclui os estados qualitativos do agente. Coisa que leva a uma nova interpretação da tese do caráter consciente dos estados mentais no sentido da consciência de se. É neste sentido que interpreto a passagem de Religion und Philosophie onde alude à atividade sensível do sujeito (Brentano, 1954: 228), e a do apêndice de 1911, em que sustenta que a relação primeira (a consciência do objeto primário) e a relação secundária (a consciência dos seus próprios estados) estão contidas (eingeschlossen) no sujeito de que fazem parte (Psychologie, p. 270).

Traduzido do francês por Pedro M. S. Alves 


\section{Referências}

Armstrong, D. (1997). "What is consciousness?". In: N. Block et al. (Eds.), The Nature of Consciousness. Philosophical Debates. Cambridge: MIT Press, pp. 721-728.

BERGMANN (1870). Grundlinien einer Theorie des Bewuss $\beta$ seins. Berlin / Amsterdam: Rodopi.

BRENTANO, F. (1889). Vom Ursprung sittlicher Erkenntnis. Leipzig: Dunker \& Humblot;

tr. fr. M. Gens, L'origine de la connaissance morale. Paris: Gallimard, 2003.

Brentano, F. (1930). Wahrheit und Evidenz, O. Kraus (Dir.). Leipzig: Meiner.

Brentano, F. (1944). (Psychologie) La psychologie d'un point de vue empirique.

Paris: Aubier, 1944; $2^{\mathrm{e}}$ éd. revue par J.-F. Courtine. Paris: Vrin.

Brentano, F. (1954). Religion und Philosophie, F. Mayer Hillebrand (Dir.). Bern:

Francke.

Brentano, F. (1975). "Was an Reid zu loben. Über die Philosophie von Thomas Reid", Aus dem Nachlaß herausgegeben von R. Chisholm und R. Fabian. Grazer Philosophische Studien, I (1975): 1-18.

Brentano, F. (1982). Deskriptive Psychologie, R. Chisholm and W. Baumgartner (Dir.). Hamburg: Meiner.

BRENTANO, F. (2008). (Shriften I) Sämtliche veröffentlichte Schriften, vol. 1, Schriften zur Psychologie, Psychologie vom empirischen Standpunkte, M. Antonelli (Dir.), Frankfurt a. M.: Ontos.

BrentaNo, F. (2009). (Schriften II) Sämtliche veröffentlichte Schriften, vol. 2, Schriften zur Psychologie, Untersuchungen zur Sinnespsychologie, W. Baumgartner (Dir.), Frankfurt a. M.: Ontos.

BRENTANO, F. (2011). (Schriften III) Sämtliche veröffentlichte Schriften, vol. 3, Schriften zur Ethik und Ästhetik, Frankfurt a. M.: Ontos.

Caston, V. (2002). "Aristotle on Consciousness". Mind, 111: 751-815.

DrETSKe, F. (1993). "Conscious Experience”. Mind, 102: 263-283.

FiseTTE, D. (2010). "Descriptive Psychology and Natural Sciences. Husserl's early Criticism of Brentano". In: C. Ierna et al. (Dir.), Edmund Husserl 150 Years: Philosophy, Phenomenology, Sciences. Berlin: Springer, pp. 135-167.

FISETTE, D. (2013). "Franz Brentano and higher order theories of consciousness" (a dar à estampa na revista brasileira Argumentos).

Gulick, R. van (2006). "Mirror, Mirror - Is That All?". In: U. Kriegel \& K. Williford (Dir.), Self-Representational Approaches to Consciousness. Cambridge: MIT Press, pp. 11-39.

Helmholtz, W. von (1879). Die Tatsachen in der Wahrnehmung. Berlin: Hirschwald. Kastil, A. (1951). Die Philosophie Franz Brentanos. Eine Einführung in seine Lehre. Bern: Francke.

Kregel, U. (2003). "Consciousness, Higher-Order Content, and the Individuation of Vehicles", Synthese, 134(3): 477-504.

KRIEGEL, U. (2009). Subjetive Consciousness: A Self-Representational Theory. Oxford: Oxford University Press.

MarTy, A. (2011). Descriptive Psychologie, M. Antonelli \& J. C. Marek (Dir.). Würzburg: Königshausen \& Neumann. 
Mulligan, K (2004). "Brentano on the Mind". In: D. Jacquette (Dir.), The Cambridge Companion to Brentano. Cambridge: Cambridge University Press, pp. 66-97. RosentHaL, D. (2004). "Varieties of Higher Order Theory". In: R. Gennaro (Dir.), Higher-Order Theories of Consciousness. Amsterdam: John Benjamin Press, pp. 17-44.

Rosenthal, D. (2005). Consciousness and Mind. Oxford: Oxford University Press. SCHELL, H (1873). Die Einheit des Seelebens aus den Principien der Aristotelischen Philosophie entwickelt. Freiburg: Scheuble.

Siewert, C. (1998). The Significance of Consciousness., Princeton: Princeton University Press.

SMITH, D. W. (2005). "Consciousness with reflexive Content". In: D. W. Smith and A.Thomasson (Dir.), Phenomenology and the Philosophy of Mind. Oxford: Oxford University Press, pp. 93-114.

\section{RÉSUMÉ}

Dans cette étude, je propose une relecture des textes principaux de Franz Brentano sur la conscience. Mon point de départ est la formulation de deux thèses sur la conscience que Brentano avance au tout début du deuxième chapitre du deuxième livre de sa Psychologie d'un point de vue empirique qui constituent le fondement de sa théorie des objets primaires et des objets secondaires. Mon hypothèse de travail s'appuie sur le principe de l'unité de la conscience qui représente la clé de la plupart des problèmes que l'on associe généralement à la théorie de la conscience de Brentano. J'examine trois de ces problèmes dans la deuxième partie de cette étude, à savoir les problèmes de la duplication, de la régression et de la complexité. Dans la dernière partie de cette étude, je propose une analyse du principe de l'unité de la conscience qui tient compte des écrits de Brentano après la publication de sa Psychologie en 1874 et j'évalue la portée des changements que Brentano apporte à sa théorie de la conscience dans ses écrits publiés à titre posthume sur les débats actuels autour de Brentano.

\section{ABSTRACT}

In this paper, I propose a reassessment of Brentano's most important writings on consciousness. My starting point is the formulation of two theses on consciousness that Brentano expresses at the very beginning of the second chapter of the second book of his Psychology from an Empirical Standpoint, which constitute the foundation of his theory of primary and secondary objects. My working hypothesis rests on the principle of the unity of consciousness, which is the key to most problems generally associated with Brentano's theory of consciousness. In the second part of my paper, I examine three of these problems, namely, the problem of duplication, that of infinite regress, and that of complexity. In the last part of my paper, I propose an analysis of the principle of the unity of consciousness that takes into account Brentano's writings after the publication of his Psychology, in 1874, and I briefly appraise the impact, on the atual debates regarding Brentano's theory of consciousness, of the modifications that Brentano has subjected his theory in several lectures and manuscripts published posthumously. 